\title{
EXPERIENCIAS DESDE LOS MÁRGENES: ANÁLISIS DE LAS TRAYECTORIAS BIOGRÁFICAS DE JÓVENES «EN TENSIÓN» EN LA CRISIS SOCIOSANITARIA
}

\author{
PATRICIA CARRASCO ${ }^{1}$ \\ DIEGO ANIÑIR ${ }^{2}$ \\ NATALIA BRAVO ${ }^{3}$ \\ ClAUdio DUARTE ${ }^{4}$ \\ NATALIA HERNÁNDEZ ${ }^{5}$ \\ ELIANÉ MARTÍNEZ ${ }^{6}$
}

\begin{abstract}
RESUMEN
En el artículo compartimos los primeros hallazgos de un proceso investigativo que pretende analizar las experiencias en el contexto de crisis sociosanitaria de un determinado grupo de jóvenes. Como parte del ejercicio interpretativo, consideramos que estos jóvenes han configurado sus trayectorias biográficas desde una posición conflictuada con determinadas disposiciones institucionales, donde enfrentan sus contextos marcados por la precarización e injusticia, pero a la vez, han construido acciones alternativas que fracturan determinados mandatos sociales. Nuestra apuesta investigativa propone relevar esta multiplicidad de posiciones de los mundos juveniles que se contrapone con parámetros normativos y homogeneizadores que predominan al momento de investigar juventudes.

PALABRAS CLAVES: REVUELTA SOCIAL, PANDEMIA, BIOGRAFÍAS, JÓVENES EN TENSIÓN CON LO INSTITUCIONAL.
\end{abstract}

${ }^{1}$ Profesora de Historia y Geografía, Universidad de Chile. Integrante del Núcleo de Investigación y Acción en Juventudes, Universidad de Chile. Correo electrónico: patricia.carrasco.barreda@gmail.com

${ }^{2}$ Sociólogo; Magister(C Estudios Latinoamericanos, Universidad de Chile. Integrante del Núcleo de Investigación y Acción en Juventudes, Universidad de Chile. Correo electrónico: diego.aninir@gmail.com

${ }^{3}$ Licenciada en Sociología, Universidad Arturo Prat. Terapeuta en Flores de Bach y Consejera de lactancia. Integrante del Núcleo de Investigación y Acción en Juventudes, Universidad de Chile. Correo electrónico: nataliabravoaraya@gmail.com

${ }^{4}$ Sociólogo y Educador popular. Académico Universidad de Chile. Correo electrónico: claudioduarte@uchile.cl

${ }^{5}$ Trabajadora Social. Doctora en Trabajo Social, Universidad Nacional de La Plata, Argentina. Integrante del Núcleo de Investigación y Acción en Juventudes, Universidad de Chile. Académica Departamento de Trabajo Social, Universidad Alberto Hurtado. Correo electrónico: nhernand@uahurtado.cl

6 Antropóloga; Magister@ Ciencias Sociales mención Sociología de la Modernización, Universidad de Chile. Integrante del Núcleo de Investigación y Acción en Juventudes, Universidad de Chile. Correo electrónico: eliane.dmartinezd@gmail.com 


\title{
EXPERIÊNCIAS DA EXCLUSÃO: ANÁLISE DAS TRAJETÓRIAS BIOGRÁFICAS DOS JOVENS «EM TENSÃO» NA CRISE SOCIAL E SANITÁRIA
}

\begin{abstract}
RESUMO
Neste artigo compartilhamos os primeiros resultados de um processo de pesquisa que visa analisar as experiências de um grupo específico de jovens no contexto da crise social e sanitária. Como parte do exercício interpretativo, consideramos que estes jovens configuraram suas trajetórias biográficas a partir de uma posição de conflito com certas disposições institucionais, onde enfrentam seus contextos marcados pela precarização e injustiça, mas ao mesmo tempo, construíram ações alternativas que fraturam certos mandatos sociais. Nossa pesquisa propõe relevar esta multiplicidade de posições dos mundos juvenis que se opõe aos parâmetros normativos e homogeneizantes que predominam no momento de pesquisar juventudes.

PALAVRAS-CHAVE: REVOLTA SOCIAL, PANDEMIA, BIOGRAFIAS, JOVENS EM TENSÃO

COM O INSTITUCIONAL

\section{EXPERIENCES FROM EXCLUSION: AN ANALYSIS OF THE BIOGRAPHICAL TRAJECTORIES OF CONFLICTED YOUNG PEOPLE DURING THE SOCIO-SANITARY CRISIS}

\begin{abstract}
In this article, we share the first results from a research process aimed to analyze the experiences of a determined group of young people within the context of the sociosanitary crisis. As part of the interpretive exercise, we consider that these young people have configured their biographical trajectories from their conflict with determined institutional regulations, where they have simultaneously confronted their contexts marked by injustice and precariousness and built alternative actions to break certain social mandates. Our research approach proposes to do research on the contrast between the diversity of stances of the young worlds and the prevailing homogenizing, regulatory parameters in youth-related research.
\end{abstract}

KEYWORDS: SOCIAL REVOLT, PANDEMIC, BIOGRAPHIES, YOUTH IN TENSION WITH THE INSTITUTIONAL 


\section{INTRODUCCIÓN}

Partimos de la constatación de que la población social nombrada como «jóvenes» es heterogénea, condicionada desde el complejo de relaciones que dan sentido y sedimento. Los primeros hallazgos de investigación acá presentados se enmarcan en una particular producción de juventudes; aquella que por diversas aperturas/clausuras ha devenido en constante conflicto con las modalidades institucionales. Nos referimos con «jóvenes en tensión con lo institucional» a quienes en sus trayectorias han reñido, enfrentado o se han resistido a algunas sino muchas - de las disposiciones que diversas instituciones sociales buscan imponer - familias, amistad, medios de comunicación, escuelas, y/o laborales, entre otros-; ante ellas han producido subjetividades diferenciadas respecto a dichos mandatos.

Las y los jóvenes son actores que construyen itinerarios que se convierten en sus decisiones y elecciones, por ende, en sus trayectorias (Dávila y Ghiardo, 2018). Ahora, sin duda alguna, esas elecciones están vinculadas con las relaciones que se establecen con las instituciones y los sistemas que conforman sus contextos. A través de estas relaciones se aprecian diversas formas de tensionarse, ya sea por las marcas que las instituciones pueden ir construyendo, como también por decidir alejarse de ciertos sistemas de creencias y sentidos (Goffman, 2001). En las trayectorias juveniles, podemos reconocer cómo estas interacciones van marcando e incluso provocando la sensación de determinación en diversas esferas de las vidas. Hay tensiones, hay fracturas, que se aprecian en sus relatos e interpretaciones, y también, la corporeización de dichas experiencias en sus cuerpos.

En la actualidad, estas tramas juveniles caracterizadas por la desigualdad e injusticia social han sido doblemente afectadas, en un primer momento por la revuelta de octubre de 2019 y luego por la subsecuente pandemia, generando una nueva panorámica de urgencias, demandas y sentires, al tiempo que los conflictos 
políticos y sociales que se venían disputando en el Chile contemporáneo se han hecho totalmente visibles para las y los jóvenes, encontrando en aquellos apuestas como también aprensiones. La articulación de estos procesos — revuelta y pandemia - converge en lo que hemos denominado crisis sociosanitaria. De este modo, con los acontecimientos de la revuelta y la pandemia asistimos a la imbricación de nuevos fenómenos que, en tanto fuerzas (des)instituyentes, dan sedimento y nuevos relieves a las dinámicas y vínculos de las juventudes aquí señalados, condicionando sensibilidades, racionalidades y acciones.

Con la nominación de crisis sociosanitaria, intentamos dar cauce a unas reflexiones en lugar y tiempo situados en que presenciamos una agudización de conflictos sociales (Parente, 2006), en momentos que los problemas se presentan como estructurales y sistemáticos, y que incluso pueden amenazar la supervivencia (Báez, 2020). Para esta investigación, la crisis del «oasis chileno» posee aristas que se pueden identificar, de modo esquemático, con una aguda concentración de riquezas y bienes públicos (Stecher y Sisto, 2019; Haerpfer et al., 2020); clausura de la participación efectiva de agrupaciones y colectivos sociales en lo institucional (Salazar, 2000); crecientes procesos de repolitización y agrupamiento generacional (Aguilera, 2016; Zarzuri, 2016); agudas sensaciones de una cultura y política autoritaria (Araujo, 2016). Con la revuelta se han hecho visibles estos fenómenos, los que se han agravado en un contexto de incesante quehacer sanitario en que, desde los mundos adultos políticos y científicos, las juventudes son invitadas a practicar el autocuidado y la responsabilización, al tiempo que se les controla y estigmatiza discursivamente (Carrasco, Araya, Olivares, 2020; Escobar, Araya, Hernández y Duarte, 2021).

Con estos antecedentes, estas trayectorias investigadas nos hablan de juventudes precarizadas económica y socialmente, en conflicto con la ley y muchas de ellas en proceso de intervención institucional asistida, por ejemplo, en dispositivos del Servicio Nacional de Menores (SENAME), con inestabilidad laboral, prácticas sociales y de consumo que muchas veces se adentran en el 
campo de lo ilegal o paralegal. Estas trayectorias, siendo consistentes en visibilizar las marcaciones sociales recién descritas, no solo son críticas respecto a su propio despliegue, también lo son respecto al mundo social que habitan, problematizando nudos y conflictos que para otros conjuntos generacionales también resultan relevantes, encontrándonos con diferencias y cercanías intergeneracionales. Estas problemáticas han quedado en evidencia y han emergido de manera constante con los conocidos informes de irregularidades y muertes en SENAME, la alta criminalización de la protesta social que tiene protagonismo juvenil, la aguda persecución y mediatización de delitos efectuados por personas jóvenes y específicas leyes de responsabilidad penal adolescente.

Reconociendo que por diversas razones y motivaciones estas juventudes frecuentan bríos diferentes a lo determinado por lo que se denomina «ciclo vital», tenemos ocasión de presenciar el despliegue multiposicional de este grupo de jóvenes y que en diversas ocasiones posibilitan una agencia propia, a modo de alternativa individual y/o colectiva a las promovidas de forma normalizadora $y$ homogeneizante por las instituciones. En este sentido, enmarcamos estas posiciones sociales conflictuadas de los actores desde su relacionalidad concreta, evitando sostener purismos de aquella tensión, sino más bien abriendo una comprensión de su sentipensar a partir de los espacios intersticiales, interculturales y liminales (Marcial, 2018) que habitan, teniendo presente a su vez, las variadas formas de etiquetaje y estigma social que se reproducen desde diversos discursos como la prensa y medios de comunicación masivos (Tsukame, 2018; González, 2021), así también de dispositivos institucionales y sociales (Albano, Castelli, Martínez y Rossal, 2015; Rettberg, 2020). 


\section{CONSIDERACIONES METODOLÓGICAS}

Para la realización de este trabajo, elegimos una metodología que nos permitiera acercarnos a los relatos de las experiencias de cada joven. Es por eso que construimos un dispositivo metodológico que articuló elementos del método biográfico-narrativo con elementos de la etnografía visual, como herramienta disparadora (Hernández, 2019).

El método biográfico-narrativo nos permitió brindar espacios para el acto de narrar, describir, y compartir experiencias de vida (Landín y Sánchez, 2019) que conforman los trayectos de los jóvenes. Se produjo, de este modo, un espacio particular y único, en que se pone al centro sus significados, sus sentidos, sus construcciones, como también sus proyecciones. Para potenciar este espacio combinamos técnicas que devienen de la etnografía visual, especialmente de la fotografía, pues buscamos que se convirtieran en un artefacto que apoyara los relatos y facilitara las formas de comunicar sus construcciones (Melleiro, 2005). Por ello, construimos dos instrumentos: un guion temático y un set fotográfico. Trabajamos con preguntas abiertas, que apuntaban a reconocer sus relatos, sus sentires, y las apoyamos con un set de fotografías que ilustran momentos de la revuelta, de la pandemia y de espacios políticos habitados por diversos sujetos sociales. Agregamos también imágenes que se pudieran relacionar con sensaciones y sentimientos, de manera libre y personal.

Trabajamos con jóvenes que se encontraban en tensión con el sistema judicial, con el mundo del trabajo, el mundo familiar y/o con el mundo educativo. Jóvenes conocedores de sus territorios, y desde ahí, capaces de anudar reflexiones con apuestas de acción. Fueron seis varones entre 18 y 27 años, habitantes de la Región Metropolitana. Nuestra intención era vincularnos con diferentes géneros; sin embargo, a través del trabajo de campo que desplegamos, descubrimos lo difícil que era llegar a jóvenes mujeres y disidencias que tuviesen semejantes trayectorias. Sin embargo, esta situación muestral no es un vacío en 
los vínculos que entablan los jóvenes entrevistados, pues la presencia de mujeres es enunciada en particulares relatos. En ellas se ha replicado lo que se ha observado en otras instancias: están dedicadas a los cuidados de niñes, y/o de la administración de los hogares, sin muchas chances de sustraerse de dichos mandatos (Córdoba e Ibarra, 2020; Madrigal y Tejeda, 2020). Este punto lo abordaremos en el siguiente apartado, cuando compartamos nuestros primeros hallazgos investigativos. En estos, trabajamos con análisis de contenido a través del abordaje de categorías construidas por el equipo de investigación (Navarro y Díaz, 1994).

\section{Primeros hallazgos investigativos}

\subsection{LAS EXPERIENCIAS DE LA REVUELTA SOCIAL}

El estallido social y el proceso de revuelta es valorado por los jóvenes como una expresión de lucha legítima de quienes sufren la desigualdad y las injusticias en Chile (Alé, Duarte y Miranda, 2020). Para estos jóvenes, lo que ha venido ocurriendo desde octubre de 2019, incluso durante la pandemia, es la consecuencia de sentirse abandonados por una clase política corrupta y por un conjunto de instituciones que también asocian a esa corrupción (Asún, RDZNavarro y Tintaya, 2021).

Igual quiero mi Chile, lo quiero, tiene harta gente corrupta sí, harta gente que abusa del poder, como Carabineros, Investigaciones, fiscalía, hasta el presidente ijaja, hasta el presidente! No me gusta mucho, por el estallido social pasan todas estas cosas, porque Chile no está bien, por eso se dio todo eso del estallido social. (E3)

Si aquí los políticos son los que roban, son los que mienten, todo, entonces ellos son los que tienen que cambiar primero, para que cambie el país. [¿Crees que es justo por lo que la gente está peleando?] Sí, obvio, están peleando por sus derechos. (E1) 
Pero todos cacharon el mote ${ }^{7}$ de que aquí es la clase política, es la que nos está cagando ${ }^{8}$, hermano, la que se hace las moneas con la gente y la gente cachó ${ }^{9}$ y estaban todos afuera, había un aire, yo sentía un aire como de entre felicidad y euforia y hermano verlo, para mí fue ¡hermoso, hermano! Así, dándole color $^{10}$, ¡fue hermoso, hermano! Ver cabros chicos, ver a las señoras, a la señora María, a la señora Juanita, al lado de la barricada, hermano, bajando por Grecia, gente que nunca había salido antes, salir, y conscientes de que esta huea ${ }^{11}$ fue porque ya no daba pa' más. (E4)

Estas expresiones del pueblo permitirían conseguir cambios y que en el país se viva justicia e igualdad.

En lo personal yo siento que hay más conciencia, en qué sentido, conciencia en que los políticos o la casta política no van a ser las personas que van a solucionar nuestros problemas, que si bien, mucha gente sigue creyendo eso. (...) A lo que yo iba, es que la gente le dejó de comprar a la Muni ${ }^{12}$, les dejó de comprar a los hueones ${ }^{13}$ del Senado, diputados, les dejó de comprar a esos hueones. (E4)

Bueno, los jóvenes están luchando por algo digno, por la educación gratuita y todas esas cosas. (E3)

Dos derivas plantean los jóvenes desde esta valoración. Por una parte, la asocian a lo que podemos interpretar como una diferenciación generacional, ya que las personas mayores de sus familias muestran miedo a los acontecimientos que estallaron con la movilización social, las protestas, las masivas manifestaciones en Plaza Dignidad, los asaltos a supermercados y tiendas, la represión, el toque de queda, los militares en la calle, personas que perdieron la vista o la vida en este proceso. El recuerdo de la traumática experiencia dictatorial

\footnotetext{
${ }^{7}$ Cacharon el mote: entendieron.

${ }^{8}$ Nos están cagando: nos están engañando.

${ }^{9}$ Cachó: entendió.

${ }^{10}$ Dándole color: exagerando.

${ }^{11}$ Hueá: cosa.

${ }^{12}$ Le dejó de comprar a la Muni: le dejó de creer a la Municipalidad.

${ }^{13}$ Hueones: referirse a una persona de forma peyorativa.
} 
ha hecho que esas personas adultas les transmitan ese miedo a los jóvenes

(Duarte, Aniñir y Garcés, 2017).

Aquí andaban esas tanquetas, como las que ocupan los pacos, esas que parecen zorrillo ${ }^{14}$, pero no son zorrillos, son de esas que ocupan los milicos, son carros de milicos, tanquetas militares, no de pacos, y ahí yo quedé así ¡oh!, ¡ya conchetumare! Y yo pensaba en mi abuela, yo pensaba en mi abuela brígido, porque mi abuela me contaba todo, me decía «no me gustaría volver a todo eso [la dictadura militar] porque yo la pasé fome (...) yo tuve la mala suerte que tu papi era chiquitito, tu tía también, entonces imagínate, y yo mujer y tu tata ${ }^{15}$ tratando como de protegernos». (E2)

Sin embargo, los jóvenes se plantean como activos ante este escenario y dispuestos a seguir en ello. La autopercepción de su rol en este acontecimiento político es como actores de este, ya sea en la primera línea contra la represión policial, como rescatistas ante esa represión, como en la solidaridad con ollas comunes y otras formas comunitarias.

Vamos a ayudar a la gente de aquí de La Aurora, que son como tres mamitas, cuatro mamitas, ellas tienen una sede. Lo que nosotros teníamos pensado hacer es cerrar con una malla, pero por dentro para que no la hagan tira ${ }^{16}$, picar ese espacio que tienen con tierra, picarlo entero y hacerle un tipo huerto, para que con eso mismo ellas puedan cocinar, colocarle tomatitos, cebollines, cilantro, zanahoria, se va a ver súper bonito. (E3)

Yo antes era rescatista, ayudaba a las personas que las herían los pacos, en una brigada. [Iba] a la plaza, pero estábamos aquí en La Cisterna cuando pasó todo aquí en La Cisterna. (...) [Se necesita] que la gente salga a la calle (...) Fui a dejar comida como a dos ollas comunes, una en el centro, con el profe Gonzalo fui a una y después fuimos a otra. (E1)

¿Qué pasó? se reconstruyó lo que se perdió en la dictadura, que fue el tejido social. A qué me refiero con el tejido social, el apañe entre vecinos, si bien en algunos pasajes o en algunos sectores no fue tanto, en algunas partes sí, ollas comunes, asambleas territoriales o alguna gente le decía

\footnotetext{
${ }^{14}$ Zorrillo: carro policial que expulsa gases lacrimógenos.

${ }^{15}$ Tata: abuelo.

${ }^{16}$ No la hagan tira: no la rompan.
} 
cabildos, más allá del término que sea colonial o no, la gente se reunía, se conocían entre vecinos, se apañaba ${ }^{17}$ entre vecinos. (E4)

Por otra parte, una segunda deriva en su reflexión, principalmente referida al enfrentamiento con fuerzas represivas y la participación en asaltos a supermercados, es concebida como parte de esas luchas. Desde sus significaciones, le otorgan legitimidad política y lo ven como una necesidad de este tipo de lucha. El fin perseguido necesita utilizar diversas formas y en eso las acciones de violencia son concebidas como parte de sus repertorios de acción. En tanto son una forma de enfrentar las violencias que el pueblo viene recibiendo desde siglos, adquieren importancia y legitimidad.

La cuestión que yo veía a los cabros tirándole camotazos ${ }^{18}$ a $\operatorname{los}$ pacos ${ }^{19}$, y ¿qué onda? ¿Qué hueá? Me motivé, y yo también, como tres locos a guata pelá ${ }^{20}, \mathrm{y}$ ¿por qué yo no? Y me saqué la polera, igual tengo mi físico marcado, y donde veían que yo era más o menos mandril, ellos me hacían caso a mí, yo los mandaba para allá y ellos iban a para allá, yo mandaba este grupo para acá y se iban para allá. Estaba como el jefe del clan, tenía un piño ${ }^{21}$ allá camoteándole ${ }^{22}$ a los pacos y a otro piño lo tenía acá reventando el Tottus. (E3)

Sí, en La Cisterna salía a chorear ${ }^{23}$, se dio la mano ${ }^{24}$, robé, ayudar a la gente en los saqueos, cuando los pacos les pegaban. Nos íbamos para la Plaza Dignidad, pero ahí a protestar no más. (E1)

Yo, hermano, yo para el estallido social, yo saquié, yo fui un culiao que anduvo saqueando, pero ¡sí, hermano! No te voy a mentir, rompí un par de vidrios, así brígidos de un supermercado, no hice más allá, fue el daño, fue de rabia hermano porque, de ver a esa gente, había gente astuta que corrió con comida y gente hueona que corrió con hueas que el día de mañana estaban todas en la feria. Yo te lo digo porque yo abastecí mi casa, compañero, abastecí la casa de mi pareja y la casa de mi mamá, y

\footnotetext{
${ }^{17}$ Se apañaban: se ayudaban.

${ }^{18}$ Camotazos: piedras.

${ }^{19}$ Pacos: carabineros.

${ }^{20}$ A guata pelá: sin polera.

${ }^{21}$ Piño: grupo.

${ }^{22}$ Camotéandole: lanzando piedras.

${ }^{23}$ Chorear: robar.

${ }^{24}$ Se dio la mano: se dio la oportunidad.
} 
mi hermano tiró mercadería para la casa de su señora con su hijo igual, hermano. Mi mente fue una acción jah, hermano, fue una acción de recuperar todo lo tuyo, cacha! ¿Sí o no? Eso fue. (E2)

También nos parece importante evidenciar de qué manera este repertorio de lucha callejera legitimado, y tomar parte en él, es una expresión de la pérdida del miedo a las autoridades. En tanto ellas, como ya señalamos, no son consideradas legítimas — por corruptas — porque defienden a quienes dominan y porque atacan a su pueblo, por lo que son significadas como un estamento al que hay que desobedecer y no temer.

Me gustaba puro pelear con los pacos, siempre, estuve en la primera línea. Perdigonazos no más me llegaban, pero hasta ahí no más. Nada, es que le tengo mala a los pacos, es que le tengo mala a los hueones. (E1)

Como decía, no los pacos, no los milicos, sino, de hecho, ese miedo a los pacos, a los milicos se perdió. (E4)

De esta manera, el proceso de revuelta es percibido y experimentado como un momento importante, en que el pueblo manifestó su descontento y deseos de cambio. Se perdió el miedo a la autoridad represiva y se buscan respuestas concretas en ese cambio.

\subsection{MOdOS DE VIVIR EL CONTEXTO PANDÉMICO}

La diversidad de modos de vivir y las posiciones que los jóvenes han construido - y siguen construyendo- durante la pandemia se contraponen a la mirada normativa representada por una serie de imaginarios estigmatizadores respecto al grupo juvenil (Carrasco, Araya y Olivares, 2020). A partir de los relatos de este grupo de jóvenes podemos reconocer múltiples aristas que se despliegan de esta experiencia, caracterizada principalmente como desagradable y que genera emociones de estrés y angustia:

(...) estrés, estrés, empezando por cuando uno quedó cesante, cuando uno piensa que no le puede tocar, le toca; por ejemplo, en mi caso, volví a pillar pega como después de cinco-seis meses ipa' la cagá! (...) pero si 
puedo describir la pandemia, «estresante la hueá», estresante pero a cagar. (E2)

No me gusta la pandemia porque ya hay mucha gente que está sin trabajo y esa gente necesita trabajar para sustentar a su familia, para tener comida en la casa o para poder parar la olla. (E3)

Dentro de las implicancias emocionales, se releva la sensación de temor generalizado, pero principalmente vinculado a la pérdida de trabajo y con ello, el futuro como algo incierto producto de la situación de cesantía, tanto en referencia a sí mismos como a su círculo familiar.

No alabo el trabajo, hermano; pero puta que se necesita, weón, y perderlo es como más estrés, el doble de estrés, sí, es como no cachai pa’ dónde ya caminar, pa' dónde virar. (E2)

Lo que me dio susto fue que mis viejos perdieran la pega, nosotros tuviéramos que ponernos a trabajar brígido. (E4)

Cabe especificar que, dentro del grupo, quien tuvo la enfermedad relaciona la sensación de temor también con el deseo de no repetir dicha experiencia.

Por fuera, yo andaba con la pera ${ }^{25}$ hasta para ir a fumarme un pito ${ }^{26}$ a la casa de un amigo, porque puta estoy recién saliendo de esta, tengo el alta hace un mes, estoy recién saliendo, andaba con temor, porque decía no quiero (...) me sentía irresponsable, me sentía conchesumare en algún momento, ipor un pito! Y si me enfermo de nuevo y andaba vuelto loco. (E2)

El temor también se manifiesta vinculado con la muerte como una posibilidad cercana no solo a nivel de afectación personal, sino también en relación con sus vínculos cercanos y familiares. Dentro de estos, hay una agudización del temor cuando se trata de generaciones mayores, ya sea dentro del círculo familiar como entre las personas del barrio donde viven.

\footnotetext{
${ }^{25}$ Con la pera: con miedo.

${ }^{26}$ Pito: marihuana.
} 
Yo era ese hueón hinchahuea ${ }^{27}$ que estaba todo el día, llegaba a caer mal porque mi miedo era perder a alguien de aquí. Mis propios amigos me decían, «no, yo perdí a una tía», mi compañero de pega me dijo «no, se murió la tía de mi mujer». Tuve un círculo que a todos se les murió alguien. (E2)

(...) de hecho, cuando mi familia tuvo Covid fue lo mismo, hermano, estaba psicoseao ${ }^{28}$ a cagar, mi mente estaba hecha mierda, no tanto por la enfermedad, sino por mi abuela. Yo decía, loco, mi vieja sí pudo haber ido no sé, de otra manera, yo ya la tenía como que, se me va a ir, se me va ir (...) pero lo que me daba lata era que yo decía «se hubiese ido naturalmente de viejita», no sé, pero que aparezca una hueá y que de la nada así, de la nada me la quitaran, me hacía pensar todos los días y más que eso. Murió mucha gente alrededor del pasaje de allá arriba, mínimo, digamos que son cuarenta casas, siete casas (...) pura gente de edad. No escuché mucho de cabros jóvenes, pero sí mucha tercera edad por aquí, las manzanas cercanas, brígido. (E2)

Se reconoce que la afectación de la pandemia, y especialmente el contagio de la enfermedad, afecta de manera diferenciada a las personas mayores, que son parte de la vejez. Al igual que en la experiencia en torno a la revuelta social, también podemos interpretar una diferenciación generacional al enfrentar emociones como el temor en el contexto de pandemia, en relación con la posibilidad de muerte cuando la otra persona generacionalmente es mayor.

En cuanto al encierro pandémico, hay dos ámbitos que podemos reconocer; por un lado, el impacto que genera la imposibilidad de encuentro con otras personas que son significativas y con las cuales hay una valoración de dicho vínculo; pero por otro lado, también se reconoce una mayor tensión en aquellas relaciones que previamente a la pandemia ya se caracterizaban como vínculos conflictivos, especialmente con algunos miembros de la familia directa.

Con la pandemia dejé de ver harta gente que he querido, amigos igual, familiares, a mi abuela no la veo, no me gusta ver a mi abuela, porque con la cuestión de la pandemia le puede pasar cualquier cosa. (E3)

(...) yo ya me llevo mal con ellos [familia], entonces los días que yo no estaba con mi polola, todo el día gritos, gritos y discusión, gritos y

\footnotetext{
${ }^{27}$ Hinchahuea: molestoso.

${ }^{28}$ Psicoseao: paranoico.
} 
discusión, fue tensa la hueá porque casi me agarro a combos hasta con mi viejo. Porque era mucho el encierro, pasaba una semana en la casa, una semana entera de lunes a domingo y yo no estoy acostumbrado. (E4)

En la casa igual estaban porfiados porque estaban choriados $^{29}$ igual del virus y el encierro. (E1)

Dentro de la diversidad de vivencias del grupo de jóvenes también identificamos aquellas posiciones que niegan la existencia de la pandemia, por tanto, no es incorporada como experiencia que tenga algún impacto en el desarrollo de sus trayectorias de vida.

Es que yo no creo en esta hueá, soy así súper reacio, pero no creo que haya Covid, no estoy ni ahí tampoco, si me da, me da. (E1)

Un punto de encuentro de estos diversos modos de vivir el contexto pandémico y los sentires y sensaciones generadas, incluso en el caso de negación de su existencia, es la valoración de los vínculos significativos para los jóvenes como lugares de refugio, ya sea con animales, amistades, familiares y/o parejas.

En ese momento había que afirmarse a la gente que tuviera más cercana. (E4)

Mi pareja es como mi pilar y mi hijo es mi motor. (E1)

Además. a mí me encantan los animales, yo tengo un perrito que es un bull terrier y ese animalito a mí me encanta (...) cuando salgo a comprar, pero voy corriendo, él va detrás mío, no se despega de mí, yo voy para allá, camino para allá y él viene para acá, él está echado ahí, yo me gano aquí ${ }^{30}$ y él va al lado mío, es súper fiel, súper amoroso. (E3)

Nada es fácil, sobre todo cuando no están tus familiares, tus seres queridos y los que más te apoyan o los que más te dicen «hijo, esto está mal o esto está bien, sigue por este camino». (E3)

Las diferentes dimensiones que son posibles desprender de la experiencia de este grupo de jóvenes respecto a la pandemia dan cuenta de la diversidad de modos de vivir el contexto.

\footnotetext{
${ }^{29}$ Choriados: agotados y molestos.

${ }^{30}$ Yo me gano aquí: me ubico acá.
} 


\subsection{ASPECTOS BIOGRÁFICOS DE LAS TRAYECTORIAS JUVENILES EN EL CONTEXTO DE CRISIS SOCIOSANITARIA}

Las actorías juveniles en cuanto sujetos sociales constituyen un universo dinámico y discontinuo, cuyas características son el resultado de una negociación-tensión entre la generalidad de la categoría y la actualización subjetiva de los individuos (Reguillo, 2013). Acercarnos a dichas tensiones nos posibilita reconocer el rol que juegan los constructos biográficos de los jóvenes en su mediación con el actual contexto de crisis sociosanitaria, permitiendo visualizar la configuración y reconfiguración de sus sentires, aspiraciones, aprensiones y apuestas de vida. Anteriormente revisamos sus experiencias con lo vivido en la revuelta de octubre, y ahora, también nos acercamos a las experiencias que se desprenden desde las condicionantes que la crisis sociosanitaria brinda. No se vive, ni se experimenta de la misma manera, y eso nos muestran con fuerza los jóvenes.

Se puede mencionar que las trayectorias de los jóvenes tienen puntos de encuentros biográficos, siendo uno de ellos su condición de clase, pues más allá de que compartan una determinada condición socioeconómica, ellos se posicionan desde lo marginal, reconociéndose como pobres y con un sentido de pertenencia e identidad con este segmento de la población.

¡No! Mi familia es pobre, todos fuman pasta base, no tengo un acercamiento con ellos muy bien, yo igual los quiero, los amo, aunque sean como sean. (E1)

Pertenezco a los pobres porque me gusta ayudar a la gente pobre, yo nací pobre, yo creo que pobre no me voy a morir porque lo que más quiero es poder tener mi casa, mi familia, mi hijo (...) pero siempre ayudo a la gente pobre, porque nací pobre y me voy a morir pobre. No me gusta la clase media tampoco, son muy sobrados ${ }^{31}$. (E3)

${ }^{31}$ Sobrados: engreídos. 
Al tiempo que manifiestan su identificación social, comparten sus aspiraciones a futuro que se sustentan en una cierta movilidad respecto a sus condiciones socioeconómicas. Reconociendo diferentes dimensiones que, por un lado, se relacionan con las proyecciones laborales y el esfuerzo para adquirir un espacio propio en donde establecerse con su familia, desplegándose tensiones por medio del cuestionamiento a las figuras clásicas del trabajo formal y la configuración de aspiraciones laborales «no apatronadas».

Igual no me gusta trabajar apatronado, entonces quiero trabajar en la calle de comerciante, como vendedor ambulante. (E1)

Si no nos ven trabajando o no nos ven en un trabajo como con contrato o asalariado, ¡ah, erí un vago, no hací nada, si erís independiente, te va como las hueas! (E4).

Pero también emerge en sus aspiraciones el ámbito educativo vinculado al deseo de movilidad. En sus hablas, se evidencia una fractura respecto a la disposición lineal y continua de la progresión educativa, pues debido a distintas razones ligadas a sus condiciones socioeconómicas y familiares, experimentaron intermitencias en sus estudios formales, no finalizando en los tiempos mandatados socialmente. Al respecto manifiestan deseos de revincularse con el ámbito educativo, ya sea para finalizar y/o continuar sus estudios formales.

Llegué hasta segundo, me falta tercero y cuarto, pero sí po', está la intención de terminarlo (...) y ¡sí! Tengo más aspiraciones, quiero entrar a estudiar (...) algo que tiene que ver con odontología. (E2)

Otro punto de encuentro de estos aspectos biográficos transversales a sus trayectorias se relaciona con lo que hemos decidido denominar acciones legítimas, entendidas como acciones que muchas veces se encuentran conflictuadas con la ley y que son realizadas por los jóvenes en su vida cotidiana desde temprana edad (robos, portonazos, asaltos, etc.), repitiéndose en el contexto de la revuelta y posteriormente en la pandemia. Dichas acciones se presentan como un mecanismo de supervivencia, en respuesta a las deficientes políticas públicas que favorezcan sus condiciones socioeconómicas, familiares y 
de su entorno, que han producido este sentimiento de abandono manifestada en sus experiencias en la revuelta social. Estas prácticas permiten visualizar las tensiones que determinadas demarcaciones sociales provocan en las trayectorias de vida de los jóvenes, quienes gestionan respuestas tanto individuales como colectivas, constituidas como legítimas ante aquellas intervenciones. De este modo, los jóvenes describen su inmersión en dichas prácticas como un acto legítimo de sobrevivencia a su contexto.

Quedé solo a muy corta edad, mi papá falleció el 2007, mi mamá el 2010, yo me dediqué a hacer puras cosas malas después cuando tenía 12 años, ahí empecé a hacer cosas malas, dejé de estudiar en el 2007, quedé en cuarto básico, quería ver bien a mis hermanos, pero no me quería ver bien yo, así que por eso hacía cosas malas para que ellos estén bien (...) prefiero que estén bien ellos que estar bien yo. (E3)

Hasta los 8 años estuve viviendo ahí en La Cisterna en caleta, calle, pero ya cuando empecé a afirmarme, tenía como 12 años, 13 años, empecé a afirmarme, como andaba choreando, tenía más edad, más brígido, no estaba ni ahí ${ }^{32}$, entonces ahí comencé a juntar plata pa' mi casa, a los 14 años yo tenía mi casa solo. (E1)

Estas acciones legítimas también tienen su imbricación en aquellas realizadas en el proceso de revuelta social y el contexto pandémico, donde la legitimidad se sustenta en una posición de protesta ante la desigualdad y la constante precarización vivida, que se agudiza con la experiencia de incertidumbre económica relatada en el contexto pandémico.

Fui para un toque de queda, estaban saqueando ahí en La Florida (...) saqueé una caja de seis pollos congelados, saqué copete, saqué arroz, saqué aceite, y todo se lo dejé a mi pareja y me quedé con dos pollos congelados, después (...) me metí al Alvi (...) estaba abierto, yo dije aquí me bajo (...) saqué fideos y yogures para llevar a la casa (...) a mi vieja, en ese tiempo le habían bajado (...) el sueldo a la mitad, entonces yo sé que le faltaba. (E4)

Yo me tuve que pasar para dentro del Tottus, había dos pilares cruzados del portón, los saqué y empezaron a abrir la puerta y todos para dentro, reventando los candados. Si está bien el estallido social, porque hay que robarle a los que tienen; el supermercado tiene en demasía, igual que los

\footnotetext{
${ }^{32}$ No estaba ni ahí: estaba desinteresado.
} 
malls, los saqueos, me traje tres plasmas ${ }^{33}$, en el Tottus me traía carros con cajas de shampoo, de carne, lo vendía, los regalaba, comíamos asado todos los días. (E1)

[Con la pandemia volví] a pillar pega como después de cinco, seis meses ¡pa' la cagá! ¿Cachái o no? Y recurrí a un punto antiguo, a un método antiguo, la recolecta de cobre, ipun! Cinco luquitas, diez luquitas ${ }^{34}$, que quizás no servían para la casa, pero para uno, el día a día, salvaba, era como ánimo. (E2)

En sus relatos dan cuenta de que estas prácticas develan una desconfianza y fractura de los jóvenes con las instituciones. A la vez, posibilitan una agencia en ellos, al buscar que estas acciones tengan un impacto beneficioso a sus vínculos, en tanto, esperan que estos «rescates» realizados lleguen a sus parejas, hijos/as, hermanos/as y/o cercanos. De este modo, aspectos biográficos desde la condición de clase y las acciones legítimas se entrecruzan y dan cuenta de la posición que los jóvenes desarrollaron durante el estallido y la actual pandemia.

Es importante visualizar que las acciones legítimas cotidianas, no asociadas al estallido y la pandemia, también son tensionadas por los propios jóvenes, pues si bien las legitiman dentro del contexto en el cual se han desenvuelto, también las cuestionan al significarlas como acciones «dañinas», que les han hecho transitar por un «mal camino».

Antes me dedicaba a robar (...) desde los 8 años que empecé a robar, hasta (...) los 19, 20, y hace como un año que cambié. Conocí una pareja, tengo mi hijo, cambié (...) no pensaba lo que hacía, ahora pienso las cosas que hago dos veces, ese soy yo, el (...) que trabaja, que la ve por su familia, que quiere vivir tranquilo, que no quiere estar más preso, ese soy yo. (E1)

Ahora no estoy haciendo nada malo, si igual me han picado las manos para hacer cosas malas (...) pero yo ya no lo hago, porque sé que si lo hago o me llego a ir detenido, voy a hacer un par de meses o un par de años, pero eso no lo quiero porque en esos par de meses o años, estaría buscando a mi hijo, o estaría mejor trabajando, (...) a mí me gusta el trabajo, ya hay que empezar a trabajar y darse cuenta de que si tú estás robando, le estás haciendo daño a una persona que con esfuerzo se lo había ganado. Pero es que yo les hago daño a las personas que realmente

\footnotetext{
${ }^{33}$ Plasmas: televisores.

${ }^{34}$ Cinco luquitas: cinco mil pesos; diez luquitas: diez mil pesos.
} 
tienen, me gusta robarles a los que tienen y me gusta ayudar a los que no tienen. (E3)

Estar en tensión es una categoría móvil, no es solo estar «en contra», o sentirse «afuera», se tensionan los aprendizajes, las apuestas, las decisiones, en medio de un sinfín de socializaciones que aparecen de vínculos, cultura, y un despliegue de aparatos que se entrelazan con los trayectos (García, 2002). De este modo, desde estas tensiones, los jóvenes buscan establecer giros en sus trayectorias de vida, que guardan relación con lo anteriormente señalado respecto a sus aspiraciones de vida donde emerge el trabajo y/o continuidad de estudios como alternativas para enfrentar sus contextos y brindar un espacio seguro a sus vínculos significativos, pues serían claves en la configuración de estos giros. Con relación a ello, se puede manifestar que estos aspectos biográficos posibilitan giros en sus trayectorias de vida que se presentan como posibilidades y alternativas. Se tensionan las determinaciones del ciclo vital, al enunciar niñeces breves que son interrumpidas por diversas razones con hechos y acciones conflictuados con la ley, y que generan este multiposicionamiento donde, aún siendo niños, adquieren roles vinculados a la adultez, tal como la responsabilidad de la crianza desde el rol de proveedor. De este modo, sus trayectorias fracturan y desestructuran la organización lineal del ciclo vital (Marcial y Vizcarra, 2014).

De este punto surge otro encuentro biográfico emergente desde la condición de género en el relato de experiencias concretas de estos jóvenes, que comprenden sus roles arraigados a un mandato social que se contrapone a sus propias trayectorias de tensión/ruptura con dichas determinaciones institucionales. Se configura una vertiente patriarcal respecto a los roles de género que los jóvenes adscriben y/o (sobre) manifiestan (Marcial y Vizcarra, 2017) desempeñar, en tanto, proveedores económicos dentro de sus roles familiares y de crianza relacionado con la idea de «llegar a ser alguien», que está muy presente en sus relatos y se constituye como el camino mandatado a transitar, para enfrentar sus necesidades socioeconómicas y laborales. Donde los 
procesos educativos formales inconclusos, si bien emergen en sus relatos, no se configuran como fundamentales para el desarrollo de sus aspiraciones más bien como posibilidades a incluir, que no necesariamente impiden sus proyecciones de vida como «adultos responsables».

Las tensiones entramadas en estos aspectos biográficos generan la posibilidad de construcción de «horizontes de esperanza» como alternativas. Horizontes entrecruzados con su condicionante de clase, las acciones legítimas y sus aspiraciones de vida, pues se plantea como una contraposición hacia las disposiciones e instituciones políticas - y no políticas-, y al mismo tiempo, como una apertura hacia acciones colectivas y/o individuales cotidianas en los territorios que habitan.

Yo creo que lo primero sería organizarse territorialmente, a qué me refiero con eso, organizarse, que los vecinos se organicen por pasaje o por sector, que se organicen y ellos tengan sus acuerdos, sus leyes muy entrecomillas, lo voy a decir entre comillas, tengan sus acuerdos, tengan sus reglas, en vez de esperar que vengan los pacos, la muni. (E2)

Que se pusieran de acuerdo todos, que si quieren surgir y tirar para arriba tienen que hacerlo, el pueblo ayuda al pueblo, así está ahora así la cosa, porque los ricos no ayudan al pueblo (...) hay harta gente corrupta sí, harta gente que abusa del poder (...) Chile no está bien, por eso se dio todo eso del estallido social.

Se puede hacer alusión, a partir de lo relatado por los jóvenes desde sus posiciones, que los horizontes de esperanza son parte de sus trayectorias de vida, y que en diversas ocasiones llevan consigo la posibilidad de cuestionar aquellos mandatos sociales arraigados en un contexto neoliberalizado. Teniendo en cuenta que en un modelo neoliberal es el individualismo el que se cristaliza en los cuerpos y en las prácticas de quienes habitan los territorios. Estas prácticas buscan no solo un bienestar desde una dimensión individual, sino también la solidaridad de su entorno o el de su contexto social. 


\section{REFLEXIONES}

Mirar nuestro actual contexto de crisis sociosanitaria cruzado por un proceso de transformación producto de una revuelta social, desde las miradas de las juventudes que se yerguen en tensión/fractura con lo institucional, permite acercarnos a otros mundos juveniles que tienden a ser invisibilizados y/o estereotipados por discursos homogeneizantes de juventud.

Por una parte, en estos momentos de crisis sociosanitaria y política es evidente la agudización del empobrecimiento en las condiciones de juventud. Sin embargo, de hecho, también visualizamos agencias propias, que se contraponen y permiten la construcción de horizontes dentro de sus trayectorias. La revuelta ha sido un acontecimiento que ha permitido confrontar y entender problemáticas que son compartidas por el resto de la población; allí el asunto de la injusticia y las sensaciones de que las cosas cambian son un motor que se ha mantenido en el curso de la pandemia. En esta, la visibilización de los problemas socioeconómicos — manifestados en aspectos como la salud, la vivienda y el trabajo - nos invita a comprender los modos de vinculación — breves, y también contrariados - que entablan con sus cercanos/as; en este sentido, las preocupaciones, el bienestar por sus mayores, sus hijos/as y parejas mujeres son parte de este entramado.

En este marco, la posición conflictuada en que se encuentran estos jóvenes no puede reducirse a una comprensión individualizada y desarraigada, pues estamos en presencia de sujetos que se vinculan de formas diversas y a veces a contracorriente de las marcaciones dispuestas. Se pueden sedimentar formas contrainstitucionales de vincularse, como también otras que actualizan formas patriarcales - en las conceptualizaciones de familia-, siendo estas zonas intersticiales el punto de arranque de las racionalidades juveniles; estar «en conflicto» se concretiza de modo situado, donde el tránsito de una práctica legítima a otra que no lo es se convierte en un campo poroso que no explica con 
variables exógenas el juego relacional que practican los jóvenes. En este sentido, las posiciones múltiples que encarnan los jóvenes se traducen en trayectorias biográficas diversas, en que no existe un hilo mecánico entre rol generacional e identidad, pues algunas de las prácticas efectuadas desde su temprana niñez ya están marcadas por el ritmo de lo que socialmente se espera de la adultez.

Con relación a ello, si bien se evidencia que la trayectoria de vida de estos jóvenes ha estado marcada por la desigualdad económica y social, además de la criminalización de sus acciones, la pobreza se ha vuelto una categoría sociocultural, es decir, un criterio de clasificación que define oportunidades, cancela expectativas, agudiza aprensiones de quienes no caben en los territorios neoliberales (Reguillo, 2013). Dentro de estas categorizaciones «marginalizadas», los jóvenes tensionan sus posiciones y enuncian posibles giros a sus trayectorias de vida.

Las tensiones son, también, producciones de las socializaciones que se van trenzando en las trayectorias. Se vivencian desde los vínculos y los escenarios de significados, como también, en los ámbitos internos de cada uno de los jóvenes. Estar en tensión es un movimiento que despliega alcances simbólicos y materiales, que son vivenciados a lo largo de las trayectorias. Reconocer ese movimiento nos acerca a las posibilidades de comprender y desplegar vínculos en pos de una sociedad para todes.

RECIBIDO: 30 DE JUNIO DE 2021 ACEPTADO: 3 DE SEPTIEMBRE DE 2021 


\section{BIBLIOGRAFÍA}

Aguilera, O. (2016). Movidas, movilizaciones y movimientos. Santiago de Chile: Ril Editores.

Albano, G., Castelli, L., Martínez, E. y Rossal, M. (2015). Violencias institucionales y reproducción de estigmas en usuarios de cocaínas fumables de Montevideo. Psicologia em Pesquisa, 9(2), 111-125. https://dx.doi.org/10.5327/Z1982-1247201500020002.

Alé, S., Duarte, K. y MedinA, D. (2020). Saltar el torniquete. Reflexiones desde las juventudes de octubre. Santiago de Chile: Fondo de Cultura Económica.

ArAujo, K. (2016). El miedo a los subordinados. Una teoría de la autoridad. Santiago de Chile: LOM Ediciones.

Asún, R., RDZ-Navarro, K. y Tintaya Orihuela, M. (2021). ¿Por qué surgen los estallidos sociales? Emociones, redes interpersonales, rituales y participación en protestas. Última Década, 28(54), 5-40.

BÁEz, F. (2020). Ciudadanía, libertad individual, derechos sociales e incertidumbre: Los estallidos sociales antineoliberales y la pandemia del COVID-19. Revista Faro, 2(32), 1-6.

Carrasco, P., Araya, C. y Olivares, J. (2020). Reflexiones sobre la visibilización de lo juvenil por la prensa escrita chilena, en contexto de pandemia. Última Década, 28(53), 5-39.

Córdoba, M. e IBARra CASAls, D. (2020). ¿Varones construyendo espacios de Igualdad? Desafíos en contexto de confinamiento (COVID-19). Revista Punto Género, (13), 50- 65. https://dx.doi.org/10.5354/07190417.2020.58191

DuArte, K., AniÑIR, D. y GARCÉS, A. (2017). De encuentros y desencuentros entre jóvenes y personas adultas a propósito de salir de la enseñanza secundaria en Chile. Revista Latinoamericana de Ciencias Sociales, Niñez $y \quad$ Juventud, 15(1). https://doi.org/10.11600/1692715x.1512307032016

Escobar, S., Araya, C., Hernádez, N. y Duarte, C. (2021). Construcción social de la participación juvenil: imaginarios adultos y miradas desde estudiantes secundarios. En INJUV, Problemáticas y desafios de las juventudes en Chile. Evidencias desde las Encuestas Nacionales de Juventud. Departamento de Planificación y Estudios. Santiago de Chile: Instituto Nacional de la Juventud.

GARCÍA, N. (2002). Culturas populares en el capitalismo. Barcelona: Grijalbo.

GONZÁLEZ, Y. (2021). ¿Una «convulsión generacional»? Jóvenes, etiquetaje y estigma en la rebelión de octubre. Última Década, 28(54), 95-113. 
GofFMAN, E. (2001) Internados: Ensayos sobre la situación social de los enfermos mentales. Buenos Aires: Amorrortu.

Haerpfer, C., Inglehart, R., Moreno, A., Welzel, C., Kizilova, K., DiezMedrano, J. M., Lagos, P., Norris, E., Ponarin, B. Puranen et al. (eds.) (2020). World Values Survey: Round Seven-Country-Pooled Datafile. Madrid y Vienna: JD Systems Institute \& WVSA Secretariat. doi.org/10.14281/18241.1

HERNÁNDEZ, N. (2019). Transformación social y juventudes, una mirada a sus tácticas y estrategias. Última Década, 52, 107-122.

Landín Miranda, M. Del R. y SÁnchez Trejo, S. I. (2019). El método biográfico-narrativo: una herramienta para la investigación educativa. Educación, 28(54), 227-242. http://dx.doi.org/10.18800/educacion.201901.011.

Madrigal Rajo, L. y Tejeda Guardado, W. (2020). Hombres de cuidado ¡en emergencia! Los Cuidados y masculinidades en el actual contexto COVID-19 en Centroamérica. Revista Punto Género, (13), 109-130. http://dx.doi.org/10.5354/0719-0417.2020.58196

MARCIAL, R. (2018). Fronteras juveniles y delito. Última Década, 26(50), 180197.

Marcial, R. y VizCARRA, M. (2017). Puro Loko de Guanatos: masculinidades, violencias y cambio generacional en grupos de esquina de Guadalajara. Guadalajara: Universidad de Guadalajara/El Colegio de Jalisco.

. (2014). «Porque así soy yo». Identidad, violencias y alternativas sociales entre jóvenes pertenecientes a «barrios»o «pandillas» en colonias conflictivas de Zapopan. Ciudad de México: SEGOB/Gobierno Municipal de Zapopan/El Colegio de Jalisco/CONFIN/Sistema Nacional de Seguridad Pública.

Melleiro, M. y RosA, D. (2005). La fotovoz como estrategia para la recolección de datos de investigación etnográfica. Revista Ciencia y Enfermería, (XI), 50-60. http://dx.doi.org/10.4067/S0717-95532005000100006

PARENTE, G. (2006). Teoría de la crisis. I Jornadas sobre gestión de crisis: «Más allá de la sociedad del riesgo». Facultad de Sociología de la Universidad de A Coruña, 9 y 10 de noviembre de 2005.

Rettberg, A. (2020). Violencia en América Latina hoy: manifestaciones e impactos. Revista de Estudios Sociales, 73, 2-17. https://doi.org/10.7440/res73.2020.01

SAlazAr, M. y VAlderrama, M. (comps.) (2000). Dialectos en transición: politica y subjetividad en el Chile actual. Santiago de Chile: LOM Ediciones. 
Stecher, A. y Sisto, V. (2019). Trabajo y precarización laboral en el Chile neoliberal. Apuntes para comprender el estallido social de octubre 2019. En K. Araujo (ed.), Hilos tensados. Para leer el octubre chileno (pp. 3782). Santiago de Chile: Ediciones USACh.

TsukAme, A. (2018). El rol de los medios de comunicación en la construcción de discursos en la «guerra contra la delincuencia juvenil» en Chile (19902016). Polis (Santiago), 15(44). http://dx.doi.org/10.32735/S07186568/2016-N44-1193

ZARZURI, R. (2016). Las transformaciones en la participación política de los jóvenes en el Chile actual. En M. A. GARRETón (coord.), La gran ruptura: Institucionalidad política y actores sociales en el Chile del siglo $X X I$. Santiago de Chile: LOM Ediciones. 